\title{
Understanding the Sociality of Experience in Mobile Music Listening with Pocketsong
}

\author{
David S. Kirk, Abigail Durrant, Gavin Wood, Tuck Wah Leong* and Peter Wright \\ Open Lab \\ Newcastle University \\ Newcastle upon Tyne, UK \\ \{david.kirk; abigail.durrant; g.wood2; \\ * Interaction Design and Human Practice Lab \\ University of Technology Sydney \\ Sydney, Australia \\ TuckWah.Leong@uts.edu.au
}

p.c.wright\}@newcastle.ac.uk

\begin{abstract}
Music listening practices are changing. Mobile, networked devices now offer rich opportunities not just for personal music consumption but also for personally broadcasting music and for sharing digital meta-data concerning tastes, preferences and general listening habits. However, experiences of music listening and sharing on the move and how this has been impacted by developments in mobile technology remain under-explored. In this paper we present an empirical study of the sociality of mobile music experiences, 'in the wild', using a new location-based mobile music-sharing application (Pocketsong), designed as a technology probe. We report users' experiences of Pocketsong (distilled from interviews), and critically examine the affordances of mobile music applications, the sociality of sharing and 'co-listening', and the relationships between digitally-mediated mobile music consumption and self-expression. Based upon this we reflect upon the interaction design challenges of developing mobile music technologies that work in digitally-mediated social spaces.
\end{abstract}

\section{Author Keywords}

Music; Sociality; Mobile; Self-expression; Technology Probe.

\section{ACM Classification Keywords}

H.5.m. Information interfaces and presentation (e.g., HCI): Miscellaneous.

\section{INTRODUCTION}

Music listening is a ubiquitous aspect of many people's lives. As such, there has been a significant effort within the Human-Computer Interaction (HCI) community to design technologies that better support people's interactions with music, for example helping people to navigate and search their expanding digital music libraries more efficiently and

Permission to make digital or hard copies of part or all of this work for personal or classroom use is granted without fee provided that copies are not made or distributed for profit or commercial advantage and that copies bear this notice and the full citation on the first page. Copyrights for thirdparty components of this work must be honored.

Copyright is held by the owner/author(s).

DIS 2016, June 04-08, 2016, Brisbane, QLD, Australia

ACM 978-1-4503-4031-1/16/06.

http://dx.doi.org/10.1145/2901790.2901874

(c) (1)

This work is licensed under a Creative Commons Attribution International 4.0 License effectively on computational devices (e.g. $[4,8]$ ), or exploring more expressive ways to consume music [2]. However, listening to music can also provide a resource through which social and emotional interactions are produced, and this can contribute to building ties, creating shared meanings, and constructing collective "mediated memories' [21]. In other words, people's interactions with music can shape their social experiences and personal identities; it is during their talking about, displaying, swapping, and sharing of music that people commonly express who they are [ibid].

The Sony Walkman ${ }^{\mathrm{TM}}$ arguably ushered in an era of 'private music listening experiences' in public. This became even more pervasive with the arrival of the iPod, which was criticised by many as fostering anti-social behaviour [9]. However, as social technologies (e.g. smartphones, the mobile Internet) pervade our lives, we are finding new opportunities to reinvigorate the sociality of music listening, especially in public. This provides opportunities to explore the roles that new digital technologies may play in shaping people's everyday social and collaborative experiences as well as people's use of music in processes of self-expression (e.g. $[19,21]$ ). Understanding these processes will allow us to design personal mobile music technologies that better support music listening and sharing in new digitally mediated social spaces.

This paper aims to advance our understanding of the social experience of mobile music listening and sharing by presenting an empirical study of individuals' 'in-the-wild' use of a location-based mobile music application (app) called Pocketsong, which we have designed to serve as a technology probe $[11,14]$. The design of Pocketsong was guided by insights gained from prior fieldwork on technology-mediated sociality surrounding music [19] and informed by related approaches amongst extant literature (elaborated upon later). The use of Pocketsong within our fieldwork study was to specifically support and promote reflection amongst our study participants, upon aspects of social experience during mobile music listening.

In this paper we describe our design and deployment of Pocketsong and the reported experiences of its use, distilled from interviews. We discuss our study findings about the affordances of mobile music applications, the sociality of 
sharing and 'co-listening', and the relationships between mobile music consumption and self-expression. We further reflect upon the interaction design challenges of developing mobile music technologies that work in digitally-mediated social spaces, to offer up transferable insights for the HCI community. Before turning to describe the study, we first present extant work in HCI and related fields that informs and grounds our enquiry.

\section{Studying music listening on-the-move}

With the rise of mobile devices that allow people to interact with digital music on the move, there are abundant technical prototypes and frameworks offering novel [27, 3], effective [17] and ludic [13] forms of mobile interaction around digital music listening and sharing. Significantly for our concerns for sociality herein, some of these technical endeavours have sought to stimulate social interactions amongst listeners in the public space. For example, mobile apps (e.g., PDA) allow listeners to share or broadcast their music, to tune into what others are listening to nearby [5, 20]. Other phone apps allow peer recommendations of music, and/or the exchange of music files [6, 12, 24], and even messaging between listeners [7]. However, as Leong and Wright [19] have pointed out, whilst it is valuable to demonstrate the potential of technical frameworks to connect people, what remains underdeveloped in HCI literatures is a deep and nuanced understanding of the nature of this technology-mediated sociality surrounding music interactions and the impacts that this might have on user experiences. Indeed, there is a surprising dearth of research aiming to understand how mobile music listening technologies affect sociality and how social practices affect people's interactions with that technology.

There are a few exceptions, however. Seeburger et al [23] prototyped a smartphone app aimed at allowing collocated people to share and discover song choices in public spaces. They found that the use of the app mediated some social interactions and can be engaging to users as well as piquing their curiosity about people in their vicinity. However, the findings were based only on Wizard of $\mathrm{Oz}$ simulations of the app in action; there were no evaluations of users' experiences 'in the wild'. Hakansson et al [12] further explored mobile music sharing through a field study in Sweden of Push!Music, a prototype service allowing both manual and automatic music sharing through ad hoc wireless networking, also providing a social awareness of other users nearby. They too found interesting social uses and their findings highlight the significance of selecting and sharing tracks for impression management and selfexpression; this supports earlier interview findings by Voida et al [26] on impression management in iTunes music sharing in the US. In related work, a survey of music sharing using mobile devices amongst Finnish teenagers revealed how technological affordances affected sharing practices [16], whilst another study described how Finnish 'tweens' made sense of their personal and social sharing of music on mobile devices [18]. Swedish teens were found to use the technology of mobile phones creatively for playful activities surrounding music and that music sharing was important for social interactions [15]. A more recent qualitative study of social practices surrounding digital music in the UK revealed how various recent key developments in our digital technological landscape have changed people's social practices surrounding music [19] by affording more opportunities for communicating, sharing, bonding, and celebrating lives with others through that music; Leong and Wright [ibid] found that factors such as the availability and accessibility of vast online music libraries via Internet-enabled devices, extended listeners' access to music beyond their own personal collections, and in turn changed the nature of music listening.

Whilst these extant studies have considered music consumption, our technology probe study with Pocketsong frames a new line of enquiry: we set out to understand the technology mediated sociality surrounding mobile interactions with music that are grounded in everyday personal experiences, and including public settings in which individuals are 'on the move' (mirroring recent interests in studying mobility [25]). Beyond consumption per se, our study sought to explore how practices of music listening and sharing are expressed and experienced through mobile technology use that mediates public space and social interactions. Furthermore, we sought to explore how social experiences are entangled with the affordances of mobile music applications. The Pocketsong study thus aimed to construct an experiential frame of understanding with which to unpack mobile music listening, in turn allowing us to critically reflect upon the design of mobile music technologies for use in digital public spaces.

\section{OUR STUDY}

We now describe our study design. Our original research questions were motivated by an Experience-centred Design (ECD) methodology [28] and an empirical concern for understanding 'real-world' user experience to generate pragmatic design insights. Our research questions were: (1) how do people experience location-based consumption and sharing of digital music in a mobile and public setting? And (2) how is social interaction/expression impacted by the emerging technological landscape of mobile music technologies? To address these questions we used a method that placed emphasis on critically exploring the social dimensions of technology use at the cutting edge of what's currently available on the consumer market, rather than exploring technical innovation through design per se.

\section{Method}

We chose a technology probe method [14] because, in keeping with our ECD approach, it enabled us to reconfigure existing technology to explore and capture data about people's interactions 'in the wild' [22]. With this objective, we present our smartphone app, Pocketsong, not so much as an innovative technology per se, but as a device to push certain features of interaction on our participants to 
explore how they would respond. We therefore designed the new app for field deployment with a sample of research participants, to log use and invite new opportunities for interacting with and sharing digital music in everyday life and in public (amongst the participants), over the course of 12-weeks. Participation in the study involved: an introductory session run by the researchers to address Pocketsong's usability and its novel features; an interim group interview; and an exit interview after the deployment to critically discuss the participants' experiences of use.

\section{Recruitment}

Using a snowballing method, we recruited nine participants for the Pocketsong study from the local area: Elly, Michael, Andy, Kieran, Sam, Shaun, Anita, Kim and Richard (all pseudonyms) (three of whom new one another), ranging in ages from 19-36 years. Kieran and Kim were music students at our university, at times taking classes and collocated in the same building as each other; Anita was an undergraduate student at the university. The other five in the sample lived and worked locally. All described themselves as highly interested in music (the music students in particular considered themselves music experts). Through this sample representing highly musically conscious individuals (but not early adopters of new technology), we hoped to analyse extreme users, for whom the issues at play would hold particular interest and salience, and who would therefore provide valuable critical accounts of use.

\section{Pocketsong Design}

Our starting point for a technology probe design was to generate a set of sensitising concepts from previous fieldwork [19] around notions of music consumption and sharing. This highlighted music listeners' experiences of both synchronous and asynchronous sharing, their desires to operate within listening communities, sharing tastes, and the ways in which places became associated with these specific communities and anonymous but evocative encounters with new music. The concepts were used in a series of service designs and associated storyboards. Through a process of critique and collective brainstorming, we selected and developed the Pocketsong app concept. A key design feature was for the probe to support a social, but otherwise anonymised, experience (enabling us to examine tensions around self-expression in social and 'public' settings). Accordingly, within the study, whilst some participants knew each other, their use of the system was anonymous to the other users unless they explicitly 'outed' themselves to one another (by revealing their self-selected and anonymous system usernames).

To address our research questions, our mobile app needed to be: (1) an accessible music player with simple functionality so that users could focus on experiencing its novel affordances with minimal distraction from usability issues; (2) a tool for sharing music between listeners in a location-based way; and (3) a service enabling users to explore what music was being listened to proximally (both geographically and temporally, i.e. 'snooping' on what other users were listening to, nearby and/or now). This feature in particular allowed us to perturb tensions around private and public listening.

We implemented Pocketsong as an Android OS app that connected to a remote server. Pocketsong was developed to be used on any touchscreen Android device running a minimum of the 'Ice Cream Sandwich' operating system, and due to practical constraints, the app was installed on a variety of Android phones with differing form factors. The app used tabbed pages giving the user convenient access to the majority of music functions. The app opened with users choosing music through the standard music player paradigm of selection by artist, album, track name and playlist (see Figure 1). As expected in this paradigm, once a selection was made on any given tab then the subsequent selections would be refined by that choice, (e.g. selecting the composer Beethoven might narrow the choice to the collection "Beethoven Symphony 5").

The locative functionality of this music player was accessible on the last tabbed page (see Figure 2). This tab allowed users to explore what people around them were listening to. During the design development, we envisaged that the number of adopters of the software could be anything from a dozen to hundreds, so this screen was designed to display the most recent track regardless of how long ago they were played. The tracks were initially ordered by the current relative distance to the user, and, optionally, the elapsed time. The most recent track or the closest listener was always shown first. If available, the album art from the track was downscaled into a square and given an appropriate dimension for the screen. In this way, the app arranged album covers in an ordered grid unaffected by different Android device resolutions. We used the presence of a green circle to indicate currently online listeners.

In order for the app, as a probe, to serve a critical-reflective research function, it was also designed to allow songs to be placed or 'dropped' in a geographic location, and allowed the gifting of songs to other users, thus framing alternative contexts for social exchange. Due to copyright limitations, we only exchanged a short introduction to each song (up to 15 seconds of intro), rather than the full track.

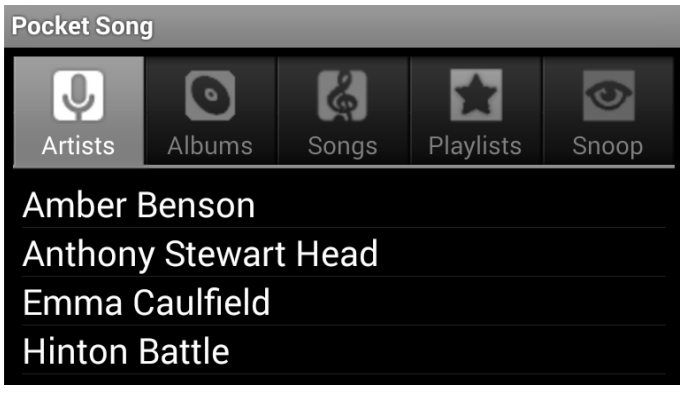

Figure 1. Pocketsong screenshot detail displaying music organised by artists 


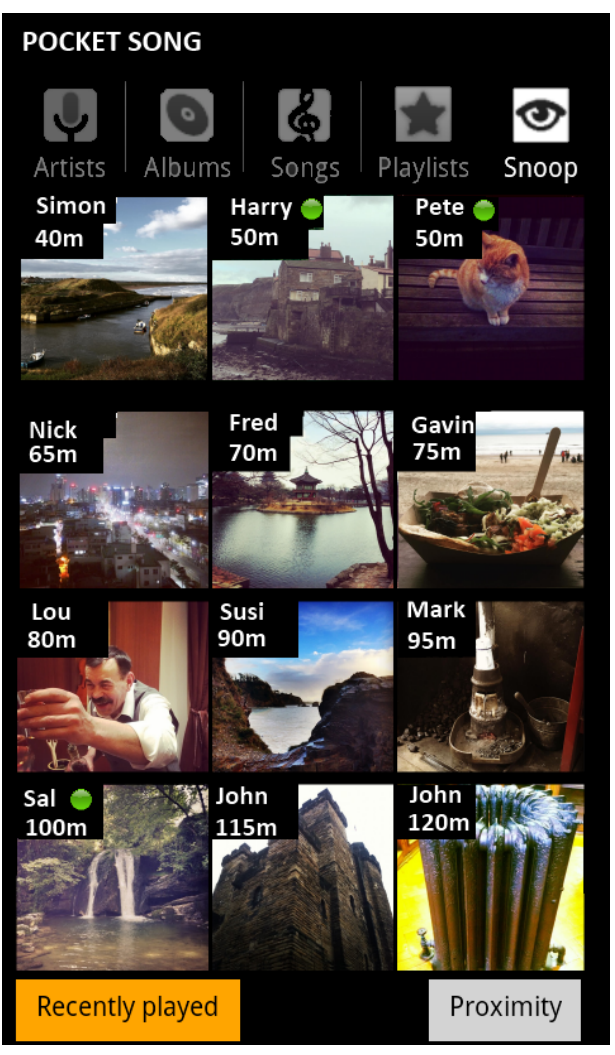

Figure 2. Music that has been played nearby, or recently

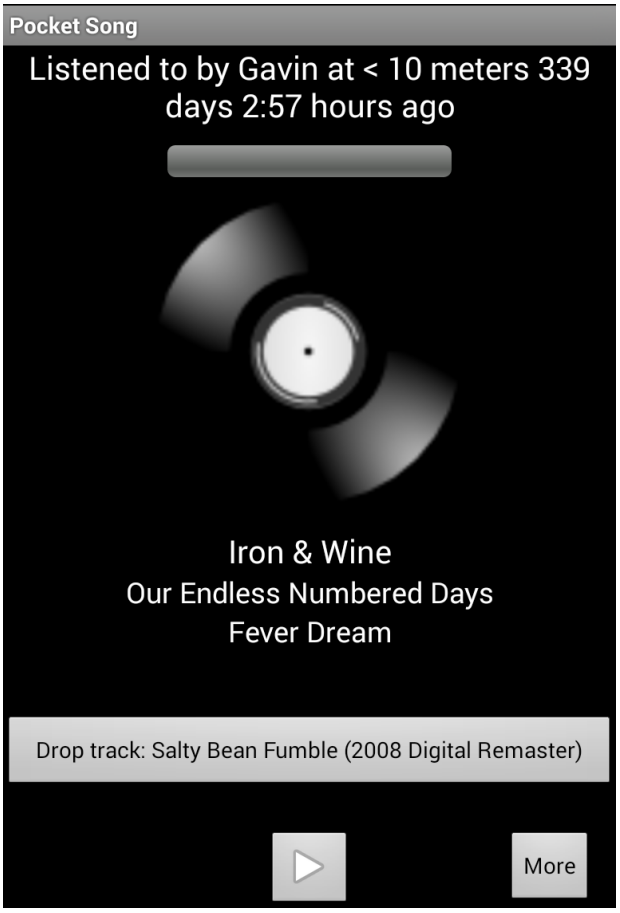

Figure 3. This user can drop a track for another user

We speculated that 'dropping' a specific track for a user would be an explicit gesture, an intention to communicate (an opening gambit as it were, in what might become an ongoing dialogue of exchanged tracks). To emphasise the intentionality behind this gesture, and give weight to the action (and possibly to avoid idle 'rick-rolling' (playful or malicious misdirection through web-links), the sender is forced to listen to the track they want to gift first (see Figure 3). The sender then selects the recipient from the list of anonymous people geographically co-present, and 'drops' the track to the other user, at that location. When that user next enters this place they are notified that a service user has dropped a track for them.

On receiving notification, the recipient of the track can add it to his/her own play list collection. This added a personal touch to the gift since playlists are normally a personal element of a music player, effectively a statement of the music that is important to you on that day. Taken together, Pocketsong's various features helped scaffold our research inquiry allowing us to potentially (and indirectly/naturally) construct certain kinds of social encounter.

\section{Procedure}

We invited our participants to attend an hour-long introductory drop-in session at our Lab before the deployment commenced. At this session, members of the research team provided participants with the app and, in some cases, an Android smartphone, and explained how they worked, ensuring that Pocketsong's novel functional features were well understood. Each participant was also provided with a 'diary application' on the phone, inviting them to make note of significant experiences and/or issues as they were to arise during the deployment, as an aide memoire. At this session, participants took part in a short interview (20min in duration) at which they were asked open questions about their music listening practices.

Around week eight of the deployment, participants were invited to one of two Interim Group Interviews (of four to five people, 30 minutes in duration) to describe their experiences of use and discuss any usability issues that they had encountered. Questions focused on use of Pocketsong and evaluation of its design, and sensed changes to everyday listening practices. Researchers also asked about application glitches and usability issues at this interview.

Although participants attended group sessions, few participants knew each other personally, in most cases they had never met. It is important to stress that their actual use of Pocketsong was effectively anonymous, as they did not know who was using what username within the system, as this was set up independently. This provided an workable level of anonymity, for the trial.

At the end of the deployment researchers held two further group interviews (one of six - Sam, Michael, Shaun, Richard, Kim and Anita; and one of three - Elly, Kieran and Andy). These lasted 90min each and consisted of in-depth, participant-driven discussion about user experiences over the course of the deployment. The interview schedule was semi-structured and many of the questions were oriented towards user experience, but others prompted conceptual 
discussion about emerging mobile music technologies and services and the forms of social interaction and selfexpression that may emerge from them. This discussion incorporated critical reflection on the Pocketsong design and led to speculation about how to develop and even reconceptualise the app and related music sharing services. All interviews were video-recorded with consent, forming a qualitative data set accompanied by logs of device/app use.

\section{Analytic Framework}

In keeping with our ECD approach [28], we adopted an interpretative, phenomenological method for analysing the data. This involved a two-stage coding procedure as a collaborative effort by the researchers. First, we generated codes from the video data relating to participants' voiced experiences and sense making in the unfolding interviews. Codes were expressed as themes supported by data excerpts. Second, the researchers analysed how the unfolding researcher-participant dialogue in each of the interviews signaled an emerging understanding about how Pocketsong experiences related to broader experiences of mobile music listening and sharing technologies. This understanding was, again, expressed in themes supported by excerpts. In turn, we used this understanding to address our research questions, collectively generating higher-level themes to be presented next.

\section{FINDINGS - POCKETSONG EXPERIENCES}

During the study we saw moderate use of the app. Amongst the participants, 681 tracks were played and there were 29 instances of gifting across the 12 week period (with $76 \%$ choosing to download the gift), with use remaining roughly consistent over the 12 weeks. In the following sections we explore in more depth some of the key features of our participants' experiences of using Pocketsong and their broader critical reflections on mobile music systems that operate between the boundaries of private and public settings. Our findings reflect three areas of interest. Firstly, we open with a discussion of the ways in which music listening and sharing is impacted by participants' concerns for self-expression. In doing so, we discuss our participants' reflections upon the relationship between music and selfhood and social interaction. Secondly, we explore some of our participants' responses to ideas and practices of colistening, as brought to the fore by using Pocketsong. And thirdly, we discuss some of our participants' reflections on mobile-access to music media, focusing on the affordances of mobile-phone technology and the potentials for this to shape music listening and sharing practices more broadly.

\section{Self-expression and facework in music listening/sharing} Participants often discussed the impact that Pocketsong had when making their listening practices public. This core feature raised concern for them about how they were expressing themselves to other users. When it came to broadcasting her personal playlist to other app users, Anita suggested: "I get more aware of what I listen to because I don't want people to think that I listen to Bruno Mars". In the following subsections we focus on issues raised in response to core features of Pocketsong's design.

\section{'Dropping' tracks and being presumptuous}

Participants voiced concerns related to their ability through Pocketsong to "drop" tracks for other users. Despite user anonymity, participants felt self-conscious about 'saving face', and not wanting to come across as lacking in music knowledge and 'being uncool'. Participant discussions at group interviews highlighted how sensitive an act of suggesting music to someone can actually be, and indeed this anxiety stopped a few users from 'dropping' tracks at all. For example, Elly feared being thought of as 'lame', and worried about offending other user's musical sensibilities (especially when she respected their musical credentials, she gave the example of a DJ friend (not a study participant) whose musical tastes she admired and who she would be worried of 'embarrassing herself' in front of). By contrast, Shaun felt he lacked confidence to share a track with someone because of not knowing enough about the recipient's broader listening habits, as he explained:

"I'd mentioned before not being able to see the full profile history of people, you know. It was one thing seeing someone play an Orbital track, but I don't know if what I'm listening to would be relevant, just because they listen to that Orbital track and that's all that I know, or that they listened to a Clash song recently, like that's a tiny proportion of a person's taste and what they're about, so it's very hard to say 'oh they've listened to that Clash song so I'll send them this', I wouldn't want to do that because I think it's a bit rude and presumptuous to go 'you've listened to that so there you go"'.

Shaun's excerpt above effectively describes what recommender systems do, but somehow the inclusion of human agency in Pocketsong rendered this kind of functionality a potentially offensive gesture - and possibly "a bit rude and presumptuous". This might be because of the ways in which socially we ascribe intentionality to the acts of others, in a way we might not with a machine.

\section{Maintaining face whilst broadcasting and 'snooping'}

In discussion of Pocketsong use, participants also collectively voiced how their listening practices had been changed, not just through desiring to present a certain image of themselves, but also by anxieties of feeling overlooked by others. In Sam's words:

"I knew people would be able to see what I was listening to so therefore I wouldn't listen to intros to albums or interludes because it's not very interesting for people to listen to, [...] But I did change my listening habits a little bit with playing more individual songs, rather than playing full albums, which is what I always do. So I was trying to make it more interesting for other people who were using the snoop."

What is particularly interesting here is how Pocketsong was pushing users, such as Sam, to shape their listening not just for their consumption but explicitly for the consumption of 
others. This moved beyond trying to maintain cool, actually shifting from consumption to broadcast as an orientation to the music player and one's relationship with it. This accentuates the social nature of music listening, arguably reversing the criticisms of private headphone 'cocooning'.

The 'snooping' function held particular interest for Elly, given the anxieties around being observed by others. She saw it as a way of circumventing embarrassment in asking for music recommendations from her friends she viewed as having greater musical knowledge:

"If you were friends with people then I think I'd feel more like 'oh I definitely want to snoop on this person' because you know who they are and you might respect their music tastes, but you don't really know what they listen to. I've a friend who's a DJ and I'd love to snoop on his songs without having to ask him every time."

For participants like Elly, the snooping function served some means of 'saving face' in the socially fraught world of music listening. As such, the snooping tool offered a mode of listening that circumvented (in some cases) anxieties around sharing. However, as the findings above illustrate, music sharing makes for complex social experiences.

Notions of cool, and doing musical facework (i.e. saving and maintaining face) to generate cultural capital ${ }^{1}$ [1] amongst a user's social group, was a phenomenon frequently noted by our participants. Observable music consumption and the implication of possessing music knowledge was seen as a way of self-identifying with certain groups, or as a way of differentiating oneself from the perceived mainstreams. The value of 'obscure' music, or music that was seen to be 'obscure', was an important measure for most users in the study. Significant here is that our sample included music students and required the selfselection of participants who were interested in music so it is likely that we gathered a sample who might be inherently more image-conscious around matters of music taste.

Of equal importance was being seen to have an eclectic musical taste. This particular concern was linked in talk to anxieties about others 'snooping' on an individual's listening practices. Similar to his concerns about suggesting tracks for others, Shaun worried that Pocketsong only presented a glimpse of his actual listening habits, and therefore it didn't accurately communicate something about his 'self-image' that he might want to express to others:

"I've got a hugely broad spectrum of music, it would be very hard to define somebody by three or four tracks that they might listen to."

Mike added to this the value of demonstrating eclectic interests by talking about the importance and growth potential of music sharing for 'identifying difference':

\footnotetext{
${ }^{1}$ Bourdieu's [1] concept of assets (e.g. skills, knowledge, tastes, goods, credentials etc.) defining our social position.
}

"Identifying differences and just finding something to talk about, I mean, everyone likes a little bit of disagreement. [...] That's how music evolves I think, through disagreement and conflict."

Mike felt that sharing tracks to provoke or stimulate conversation or debate about a conflict of taste was an interesting mode of social expression through music. He suggested that seeking out difference rather than common ground helped to evolve musical tastes, which is something he saw as a positive value in a music sharing technology.

\section{Being part of a localised listening community}

Whilst difference was seen as important for identity, similarity in taste was also discussed as significant. Richard described his excitement about being in a listening community of like-minded people interested in particular sub-genres of music. And Shaun explained that he would only share music if he sensed that there were similarities to his own tastes, and related that to the formation of friendships at school and beyond, claiming that his circle of friends all listen to the same kinds of music:

"The reason we are all friends is because we kind of liked the same music at the same sort of time. [...] I have quite a lot of common ground musically with a lot of my core friend group."

Interestingly, Sam and Shaun went further to speculate about potentially localised music listening communities arising in public spaces explicitly because of the use of locative technologies such as Pocketsong:

"Maybe there's a possible tendency for having certain areas where you'd have more of a correlation between what's playing - maybe high streets would be a huge mix of stuff, but there are certain areas where certain people hang, so what's the mix of genres around the university?" [Sam].

Kieran felt that a person's expression of who they are to others, and how that self-image is maintained, is strongly connected to an expressed knowledge of and 'critical engagement' with music. He framed the effort of finding out about music, being the person who knows the yet-to-bediscovered bands, and being the trendsetter, as core to developing cultural capital:

"I suppose there's a prestige that comes from having gone through the work, then it's considered that you've had a critical engagement with a field of music, and you've chosen something as opposed to someone else doing that critical work and then coming along to you in a bar and going 'you should listen to this' and then you've kind of just had that shortcut."

Accordingly, Anita felt that she was justified in imposing her music collections on her friends. She had self-belief in the value (in terms of cultural capital) of her tastes, which gave her a sense of obligation and right to share her music:

"I share music so that my friends also like it, I mean I believe what I listen to is cool music, right? So I just 
force people to listen to those things as well, so I usually send them links from YouTube and say 'just listen to this, this is really good' and often they go 'no' but I just keep doing that, because I think you should just share good music and if you find something that is, I don't know, some indie bands that no one's ever heard of you just share it."

Of particular note here is Anita's demonstration of the way in which 'newness' might be used to support the development of cultural capital - it being one way to demonstrate your insider knowledge.

These discussion points about self-image, taste and cultural capital led on to talk about the establishment of digital media profiles, through which users could actively manage their self-image through a music app. Appreciating the significance of music technology in establishing self-image is critical to understanding the social anxieties present in the talk amongst participants. As Michael demonstrated, any music played in a digital public space and through social media platforms has the potential to trigger concerns about identity and sociality:

"It seems to be a kind of a stake in identity being played out, it's like a personal investment you make in trying to assert your own identity and trying to ascertain someone else's and trying to gauge compatibility on those terms. Maybe it's less benevolent than saying 'I want to share this music because I think you might like it' and more 'I'm going to share this music because I want you to know what I'm all about and I want to figure out if we can be friends or something, you know what I mean, there seems to be a deeply psycho-social thing being insinuated I think."

Of further interest is a latter point made by Shaun, who, returning to his previous comments on music territories in towns, drew a distinction between his 'real' profile and a profile he might choose to present to others:

"If you wanted to get into a scene, you noticed there was a scene at the bus station, then you might go 'I'm going to get into that scene and I'm going to tailor my profile accordingly, but I'm going to keep my real profile aside"'.

Here Shaun acknowledges that an open profile is potentially problematic when infiltrating certain music communities because of the credentials you might need to demonstrate for group acceptability. In discussing this Shaun was effectively advocating that apps like Pocketsong could benefit from actively supporting multiple expressions of self through manipulable online profiles.

\section{Practices of Co-listening}

Much discussion about Pocketsong experiences focused on how the app presents information about the current or recent listening practices of other users. Connected to this, participants talked about how the dropping of tracks affords shared, if asynchronous, listening experiences because you have to listen to a track before you can drop it). Leading from this, our participants talked about their experiences of listening to music together and how this may or may not be impacted by apps like Pocketsong. We focus here on the ways in which they wished to share music experiences.

\section{Framing a context for interaction}

For Kieran, there was definite concern for how the act of sharing music, when digital (and remotely) achieved, might inevitably lack an empathetic connection, rendering it inappropriate. He described the potentially problematic disconnect between your current interest in a track and someone else's receptivity to concurrently hearing it:

"It's not always clear what's going on at the other end of a computer interaction and so when somebody rejects something it reminds you of 'oh yeah that other person could be in a completely different space, [...] a different mood'. So sometimes when [...] you're like, having a great Fleetwood Mac experience for a minute, and you're like 'I must send this to Brian or whoever', and it's just not that moment when the other person is just waiting around for your great Fleetwood Mac recommendation [...] I have to remember to try and empathise with what the other person might be doing."

In this comment, Kieran suggested that technology platforms, particularly ones that rely on remote sharing, have significant potential to decontextualise social exchanges. Users' experience of Pocketsong sensitised them to this concern, resulting in a general agreement at the group interviews for a need to validate or assert one's motivations for sharing - a need to qualify just why the act of sharing was being enacted.

For some users the talk of sharing tracks made them think quite seriously about how face-to-face music listening (colistening) was different to digitally-mediated co-listening. Whilst an advantage was seen in the instantaneous nature of sharing digital tracks at a distance, it was felt that the lack of physicality in sharing meant that the mobile interface was a poor substitute for seeing people when exchanging music; as Michael elaborates:

"I think the most striking affordance in terms of mobile technology and broader, perhaps the Internet as a whole, is just the lack of palpable proximity with people, $[\ldots]$ you can still communicate with these phones but I guess when you're sharing music through them it's easier for the person on the other end to hide the fact they don't like it or ignore it altogether."

"I think mobile technology can only be so social, I think it's always going to be derivative of real [...] but physical proximity, and even having the markers of where people are at on the app for instance, where you can see who listened to what in a certain place, that's still not quite the same as seeing somebody and seeing the look on their faces or what they're mumbling under their breath" [Michael]. 
Significant for our analysis is the attention given to reciprocality that Michael is expressing here. He has identified the subtle cues of social and situated interaction, highlighting how digital and mobile exchange as constructed through Pocketsong might lack this subtlety.

\section{Synchronicity of experience}

Building further on the notion of physical co-presence being valued and yearned for during moments of exchange, our participants further described valuing notions of more general synchronicity in the listening experience. The importance of having the immediacy of response to a piece of shared music, was argued to be key to the social experience of listening to music together. Michael suggested, that he wanted "more of a real time thing":

"[If] people were using it a lot, you'd have a real time 'oh people are listening to that now', I'll drop them something, see if they listen to it, that sort of thing."

Picking up on the temporality of the Pocketsong interface, our participants suggested that synchronicity might be leveraged for a rich user experience. As Kieran suggests:

"Just the idea that you could drop a track to somebody else, wait for them to push play on it, and when they push play on it, it would push play for you, and you would know that you were both listening to it and you could talk about it while you were listening to it, that seems to me that would kind of be, it's something that, it's a version of something that people do, right?'

When Kieran suggests that this a version of "something that people do' he is referring to physical co-present sharing practices and he's suggesting that digital tools might be designed to better leverage these practices. Whilst this in and of itself isn't necessarily an original idea it does highlight the importance of a sense of shared experience in music consumption being a valued feature of Pocketsong use, and something which a push towards mobility and in essence individual/headphone listening could still support. Important to note as well is that Kieran's thoughts focused on temporal synchronicity and not spatial synchronicity suggesting that the shared experience need not necessitate a simulation of physical co-presence to be satisfying.

\section{Mobile-access to music media}

As a mobile app, Pocketsong framed a research context for experiences with music centred on mobility and interacting through a smartphone. This framing further prompted interesting participant reflection on our research questions.

\section{Emotional engagement on the move}

When discussing music apps with participants a prominent consideration was the nature of pervasive access to libraries of music and information, and specifically how that access facilitated ad hoc listening practices, which might in turn have certain emotive uses. Listening to music on a phone meant it could be used for "drowning out ambience, of shutting off the noise of the bus and people chatting and things like that" [Andy], through headphone listening in public spaces so that people could be "closing themselves off in their own little bubble" [Andy] and as an opportunistic means for enhancing conversations with friends by having what they are currently listening to "there in your hand" [Mike]. Opportunistic listening also meant users could find a balance between emotional and musical expression. Participants described how music helped them manage emotions: "you can manage emotion with a good or bad record" [Kieran]. They also described music as having the power to exorcise or intensify emotional feeling: "if I'm feeling a bit angry then I might want to further my anger by putting on something that will make me even more angry" [Elly]. As such, we learned that music listening through pervasive technologies such as mobile phones actively afforded and mediated, in a moment-by-moment basis, emotional interactions with the world, and this was a feature of the experience of use that was actively valued.

Participants also had interests in the more visceral experiences that Pocketsong might offer. Discussion revolved around the 'snooping' features, with Mike arguing that Pocketsong was 'sneaky', and a way to 'spy' on others:

"When it's got a button called snoop on it, there's something quite sneaky about it, it's like a really streamlined little spy tool, so maybe there's some fun to be had with that in my head. [...] It's not sinister, but you know what I mean, right? It's a bit like 'wow what's that'? $[\ldots]$ it's all a bit shrouded in mystery isn't it?"

Echoing Mike, several of the participants expressed values they held in the snoop functionality in terms of it delivering a vicarious thrill through surreptitiously listening in on others. This kind of possibility only really exists where there is the explicit intention to transgress emotionally labile privacy boundaries through system use, something that the HCI community rarely directly advocates.

\section{Accessing and discovering music on the move}

Participants also talked about how being tethered to a smartphone as a web-connected device afforded quick and easy access, not just to music, but also to information and news, Andy mentioned constant, easy access, particularly in terms of music discovery; he suggested that music was now 'there within a few touches of the button' [Andy]. Kieran talked about a 'powerful' musical experience whereby a mixture of 'real human contact' recommendation and the ease of access on his smartphone meant that there was a new immediacy in discovering music.

However, this ubiquitous presence afforded by smartphones meant that a lot of the work involved in finding music was taken away. Andy suggested that this fundamentally "changes the model of accessing music." He referred to himself as an avid user of his smartphone who used it to facilitate an ambient, peripheral engagement with music. He talked about how he really enjoyed "looking up random bits of information that just pop into my head, music-wise", something he saw as positive. But later in the focus group, he revisited this position to suggest that smart phones are 
like "a brain holding your hand" inferring that he felt he had sacrificed a certain amount of agency to the affordances of this kind of ubiquitous presence. He suggested that smartphones should facilitate a healthy use by becoming less like a 'crutch.' and he offered anecdotes about sitting at home with his wife, not talking, but using Facebook or their smart phones. Richard suggested that sharing and discovering music is now a lot easier because of access and the sheer amount that's available, and that this means that he feels less of an obligation to attend to it, suggesting that ubiquitous presence of music might in some way devalue it.

This discussion with participants described a value in the move towards mobility of music and pervasive access to it. At the same time however, there were clearly expressed concerns about the ways this in which this move might be devaluing or impairing our relationships to music content.

\section{MOBILE MUSIC INTERACTION DESIGN CHALLENGES}

We now turn to reflect upon the findings of our in-the-wild, UK study of Pocketsong. Critical to this reflection is that our aim was not to evaluate a product proposition. Our app is not entirely novel (for a similar technology see [5, 12, 23]). Likewise, we were not trying to propose the concept of music sharing services that utilise the digital public domain. The public sharing of listening habits already exists in various services and the online user community at large will evaluate its acceptability as a concept. Rather, what we aim to contribute to the DIS community through our study with Pocketsong is $(i)$ a set of findings which help to reveal the social complexity of mobile music listening and sharing, prompted by use of a technology probe, and (ii) a set of interaction design challenges for the development of personal music technologies that work at the boundaries of public-private space. Our proposed contribution is based upon the qualitative understanding we have generated and the values and concerns expressed through experiential reflections on Pocketsong use. Below we set out challenge areas for those who wish to design personal mobile music technologies to support social interaction in public spaces.

\section{Negotiating Online Identities}

A key area of concern for music technologies such as Pocketsong, which work in digitally mediated social spaces, is the extent to which they support the negotiated expression of online identities. Much of our participants' discussion explored ideas that can be encapsulated by the concept of music facework (after Goffman's notion of 'facework' as a form of identity management) [10]. Prior research $[12,21]$ has demonstrated that it is not uncommon to use music in identity formation and for self-expression with one's peer group and others. Perhaps less well understood, however, is the interaction design challenge to explore how this facework activity can be supported through the design of music playing (and sharing) interfaces (as even allowing for anonymity at the interface, as we have seen, does not remove the need for complex facework).
Collectively, participants argued that music they share for public consumption has to fit a certain 'style', yet this might not reflect their 'real' tastes. Likewise, participants felt that, when wishing to integrate with certain social groupings, people may desire specific, ad hoc and possibly relatively temporary profiles that enable them to maintain sufficient social cachet that they can pass unremarked amongst social circles. In essence, this suggests the maintenance of permanent playlists that might be 'snoopable' in anonymity-preserving ways. These might then be coupled with publically facing, managed (and possibly conflicting) online profiles. The challenge here is designing interaction techniques for elegantly managing trade-offs between these positions, this depending on the intelligent application of policies utilising contextdependent information based on declared or assumed relationships between users. For example, imagine an individual with a music profile that switches automatically when entering certain places and/or when specific people 'are snooping'. Equally, the notion of spatialising music across cityscapes, suggested by some participants, raises a role for location-based services in spatially defining communities of music listening.

Another, and perhaps more subtle consideration, was the expressed shift between music players being used for consumption to being used for broadcast. The indirect 'broadcasting' of leaky music players such as Pocketsong, inevitably shaped listening practices but it is rare to see tools built in to music players that allow reflexive understanding of the impact of broadcast on patterns of others listening in. There is clear design potential to support users in shaping their external playlists to have maximum impact with communities they wish to address, but this requires data about 'impact' being generated, shared and visualised, raising challenges for managing privacy and self-disclosure that have been previously identified in related work [26].

\section{Supporting co-listening on mobile devices}

Another area of challenge is how personal mobile music technologies may better support co-listening and shared experiences. Building on findings from related work on supporting social awareness and reciprocity in the active and passive use of mobile music sharing services [12], our participants discussed their experiences of co-listening from the physically co-present to the digitally mediated. They expressed a desire for shared listening experiences but valued the ability to support remote interaction that came with digital mediation. Participants framed the sharing of music experiences as something beyond physical copresence and saw no sense in attempts to recreate that copresence at a distance (in terms of physicality). What they did however express was a desire for music sharing systems that supported synchronicity, i.e. the ability to experience something in the same temporal frame as another listener. Physical co-presence was less relevant if temporal synchronicity was there to foster remote co-presence. 
However, to support this more fully participants expressed desires for better management of reciprocality, that is, tools for supporting the back channel communications that provide for a richer dialogue (a not uncommon observation with collaborative technologies [14]).

Understanding how people were responding to a shared piece of music was seen as a significant goal for collaborative interaction around that music. Equally, our participants have revealed a desire to further contextualise content that is shared. With the design of our probe, we made an explicit decision to keep Pocketsong lightweight and anonymous, but the sharing mode we designed stripped sharing gestures of their context, e.g. the reason why a given track was posted to a certain user. Without that information, it was felt that the act of sharing might transgress implicit social rules about who can share tracks with whom, when and why - issues typically worked out in our everyday interactions. Beyond this point of sharing there was also a desire to be able to observe the musical receptivity of others, again to avoid making musical faux pas by inappropriately or ineptly sharing with others.

\section{Real time access and cultural capital}

It is also important to consider the relationship between pervasive media access and processes associated with the development of cultural capital (keeping in mind that our participants identified very strongly with music as a component of their identity and may therefore be more extreme in opinion than some demographics). Our participants believed that easy access to music information was a good thing, but tied to this was a misgiving for how this access undermined carefully crafted and socialised practices of conferring status amongst peers on the basis of musical knowledge and perceptions of taste. It is not clear how music technologies and software such as recommender systems might be re-imagined to support such accumulation, expression and exchange of cultural capital amongst music listening communities, but this is potentially a very rich area of future research. And this is something that can only be done with further design exploration.

\section{Reflecting on (limited) use}

Finally, we wish to briefly reflect on some of the methodological considerations of doing this kind of 'in-thewild' research. Pocketsong was designed and developed as an experimental platform - probe - for exploring our interests in the sociality of music listening. In our study we were asking participants to alter their regular listening behaviour - by getting them to use different software/hardware to their normal practices. Like any technology probe activity [14] this intervention is bound to alter behaviour. And this is part of the challenge of doing this kind of work. Ultimately, the provocations that the design raised were grounded in participants' own activities of meaning-making in dialogue with the research team. It is their efforts to make sense of the technology that have critically informed our understanding of the roles and values of sociality in their music-listening practices.

There is potential that some may look at a study of social media use with nine participants and assume the research to be ungeneralisable or provide sufficient insight in to the design of a mass media platform intended to work at scale. We would argue that this is a trade-off. Forced large-scale adoption does just as much damage to the validity of a study. Equally, launching a 'service' and waiting for mass adoption before you can do research seems wasteful. Our approach herein has been to use the technology in probe mode, and in a long tradition of more phenomenological research [see 28] we have developed a qualitative account, which considers the idiographic features of our users' experiences. And from this relatively limited amount of system use we have generated significant insight as to the moral ordering of social behaviour around music listening and sharing as it might pertain to mobile practices.

\section{CONCLUSION}

We have reported on a field study exploring social experiences of music listening and sharing in public spaces mediated by digital technology. To support this we designed and deployed Pocketsong, a location-based mobile application and technology probe. Our aim through this study was to produce valuable transferrable insights for designing future mobile music technologies. Our findings address mobile access to music media, practices of 'colistening' and relationships between digitally mediated mobile music consumption and self-expression. We raise three interaction design challenges for critical reflection during the development of mobile music applications, focusing on the negotiation of self-expression to others, support for co-listening and the development of cultural capital through interface design. By addressing these challenges we have arguably foregrounded the significance and complexity of the social experience of mobile music listening afforded by emerging pervasive technologies.

\section{ACKNOWLEDGMENTS}

We thank our research participants for their time and contributions, and musician Jamie Thompson for his support with the study. This work was supported by EPSRC Social Inclusion through the Digital Economy (SIDE) [EP/G066019/1] and AHRC KE Hub for the Creative Economy [AH/J005150/1] grants. The second author is additionally supported by The Leverhulme Trust [ECF2012-642].

Data supporting this publication is openly available under an 'Open Data Commons Open Database License'. Additional metadata are available at: 10.17634/082922-1. Please contact Newcastle Research Data Service at rdm@ncl.ac.uk for access instructions.

\section{REFERENCES}

1. Pierre Bourdieu (2011). The forms of capital (1986). Cultural theory: An anthology, 81-93. 
2. Miguel Bruns Alonso \& V. Keyson. 2006. MusicCube: a physical experience with digital music. Personal and Ubiquitous Computing, 10 (2-3), 163-165.

3. Lynne Baillie, David Beattie and Lee Morton. 2011. Feel what you hear: haptic feedback as an accompaniment to mobile music playback. In Proceedings of Interacting with Sound Workshop: Exploring Context-Aware, Local and Social Audio Applications (IwS '11). ACM, New York, NY, USA, 16. DOI=http://dx.doi.org/10.1145/2019335.2019336.

4. David Bainbridge, Brook J. Novak, and Sally Jo Cunningham. 2010. A user-centered design of a personal digital library for music exploration. In Proceedings of the 10th annual joint conference on Digital libraries (JCDL '10). ACM, New York, NY, USA, 149-158.

DOI=http://dx.doi.org/10.1145/1816123.1816145

5. Arianna Bassoli, Julian Moore, and Stefan Agamanolis. 2006. tunA: Socialising music sharing on the move. In Kenton O'Hara and Barry Brown, Eds.Consuming music together. Springer. p.151-172

6. Arianna Bassoli, Johanna Brewer, Karen Martin, Paul Dourish, and Scott Mainwaring. 2007. Underground aesthetics: Rethinking urban computing. Pervasive Computing, IEEE 6, 3, 39-45.

7. Stephan Baumann, Björn Jung, Arianna Bassoli, and Martin Wisniowski. 2007. BluetunA: let your neighbour know what music you like. In $C H I$ '07 Extended Abstracts on Human Factors in Computing Systems (CHI EA '07). ACM, New York, NY, USA, 1941-1946. DOI=http://dx.doi.org/10.1145/1240866.1240929

8. Janne Bergman, Jarmo Kauko, and Jaakko Keränen. 2009. Hands on music: physical approach to interaction with digital music. In Proceedings of the 11th International Conference on Human-Computer Interaction with Mobile Devices and Services (MobileHCI '09). ACM, New York, NY, USA, Article 33,11 pages.

DOI=http://dx.doi.org/10.1145/1613858.1613901

9. Michael Bull. 2007. Sound Moves: iPod culture and Urban Experience. Routledge

10. Erving Goffman. 1959/1990. The Presentation of Self in Everyday Life. Penguin

11. Connor Graham, Mark Rouncefield, Martin Gibbs, Frank Vetere, and Keith Cheverst. 2007. How probes work. In Proceedings of the 19th Australasian conference on Computer-Human Interaction: Entertaining User Interfaces (OZCHI '07). ACM, New York, NY, USA, 29-37. DOI=http://dx.doi.org/10.1145/1324892.1324899

12. Maria Håkansson, Mattias Rost, ,and Lars Erik Holmquist. 2007. Gifts from Friends and Strangers: A study of Mobile Music Sharing. In Proceedings of
European Computer Supported Cooperative Work (ECSCW), Kluwer, pp. 311-330.

13. Sebastian Huber, Markus Schedl, and Peter Knees. 2012. nepDroid: an intelligent mobile music player. In Proceedings of the 2nd ACM International Conference on Multimedia Retrieval (ICMR '12). ACM, New York, NY, USA, , Article 57,2 pages. DOI=http://dx.doi.org/10.1145/2324796.2324862

14. Hilary Hutchinson, Wendy Mackay, Bo Westerlund, Benjamin B. Bederson, Allison Druin, Catherine Plaisant, Michel Beaudouin-Lafon, Stéphane Conversy, Helen Evans, Heiko Hansen, Nicolas Roussel, and Björn Eiderbäck. 2003. Technology probes: inspiring design for and with families. In Proceedings of the SIGCHI Conference on Human Factors in Computing Systems (CHI '03). ACM, New York, NY, USA, 17-24. DOI=http://dx.doi.org/10.1145/642611.642616

15. Petra Jarkiewicz, My Frankhammar, and Ylva Fernaeus. 2008. In the hands of children: exploring the use of mobile phone functionality in casual play settings. In Proceedings of the 10th international conference on Human computer interaction with mobile devices and services (MobileHCI '08). ACM, New York, NY, USA, 375-378.

DOI=http://dx.doi.org/10.1145/1409240.1409292

16. Sari Komulainen, Minna Karukka, and Jonna Häkkilä. 2010. Social music services in teenage life: a case study. In Proceedings of the 22nd Conference of the Computer-Human Interaction Special Interest Group of Australia on Computer-Human Interaction (OZCHI '10). ACM, New York, NY, USA, 364-367. DOI=http://dx.doi.org/10.1145/1952222.1952303

17. Michael Kuhn, Roger Wattenhofer, and Samuel Welten. 2010. Social audio features for advanced music retrieval interfaces. In Proceedings of the 18th ACM international conference on Multimedia (MM '10). ACM, New York, NY, USA, 411-420. DOI=http://dx.doi.org/10.1145/1873951.1874007

18. Vilma Lehtinen and Lassi Liikkanen. 2012. The meanings of music sharing in tween life. In $C H I$ ' 12 Extended Abstracts on Human Factors in Computing Systems (CHI EA '12). ACM, New York, NY, USA, 1907-1912. DOI=http://dx.doi.org/10.1145/2212776.2223727

19. Tuck W. Leong and Peter C. Wright. 2013. Revisiting social practices surrounding music. In Proceedings of the SIGCHI Conference on Human Factors in Computing Systems (CHI '13). ACM, New York, NY, USA, 951-960.

DOI=http://dx.doi.org/10.1145/2470654.2466122 
20. KuanTing Liu and Roger Andersson Reimer. 2008. Social playlist: enabling touch points and enriching ongoing relationships through collaborative mobile music listening. In Proceedings of the 10th international conference on Human computer interaction with mobile devices and services (MobileHCI '08). ACM, New York, NY, USA, 403-406.

DOI=http://dx.doi.org/10.1145/1409240.1409299

21. Kenton O'Hara, K. and Barry Brown, 2006. Consuming music together: social and collaborative aspects of music consumption technologies. Springer

22. Yvonne Rogers. 2012. HCI Theory: Classical, Modern and Contemporary. Morgan Claypool

23. Jan Seeburger, Marcus Foth, and Dian Tjondronegoro. 2012. The sound of music: sharing song selections between collocated strangers in public urban places. In Proceedings of the 11th International Conference on Mobile and Ubiquitous Multimedia (MUM '12). ACM, New York, NY, USA, , Article 34, 10 pages. DOI=http://dx.doi.org/10.1145/2406367.2406409

24. Atau Tanaka, Guillaume Valadon and Christophe Berger. 2007. Social mobile music navigation using the compass. Proceedings of the International Mobile Music Workshop, Amsterdam.
25. John Urry. 2007. Mobilities. Polity Press

26. Amy Voida, Rebecca E. Grinter, Nicolas Ducheneaut, W. Keith Edwards, and Mark W. Newman. 2005. Listening in: practices surrounding iTunes music sharing. In Proceedings of the SIGCHI Conference on Human Factors in Computing Systems (CHI '05). ACM, New York, NY, USA, 191-200. DOI=http://dx.doi.org/10.1145/1054972.1054999

27. Xinxi Wang, David Rosenblum, and Ye Wang. 2012. Context-aware mobile music recommendation for daily activities. In Proceedings of the 20th ACM international conference on Multimedia (MM '12). ACM, New York, NY, USA, 99-108.

DOI=http://dx.doi.org/10.1145/2393347.2393368

28. Peter Wright and John McCarthy. 2010. ExperienceCentred Design: Designers, Users, and Communities in Dialogue. Morgan and Claypool Publishers 